\title{
Towards sustainable topographic mapping
}

\author{
Haico van der Vegt ${ }^{\text {a }}$, Ton van Helvert ${ }^{\text {a }}$, Paula Dijkstra ${ }^{\text {a }}$ \\ ${ }^{a}$ Cadastre, Land Registry and Mapping Agency of the Netherlands
}

Keywords: Topographic Mapping, SDI, Sustainability

\begin{abstract}
:
"Everything happens somewhere", a popular phrase nowadays to emphasize the importance of good and reliable geographic information. National Spatial Data Infrastructures (NSDI) are popping up in many countries in the world as governments realize that a wealth of geo-data is produced, but that this data is not known or available to other organizations. An NSDI channels this information to the users. Availability of geo-information and efficiency in the production are the key drivers.
\end{abstract}

Another big driver is the Sustainable Development Goals (SDG). To monitor the development of the progress of the SDG's, a wealth of statistical information on economic, social and environmental phenomena is collected. All this data is referring to a specific place on earth. Therefore, good and reliable geo-information is critical for the development of the SDG's of a country.

Topographic maps describe the land that belongs to a country, its sovereign territory. But they are also used for orientation, for the defense of your country, as a time stamp of how your country looks like at a specific moment in time, and many other applications. Topographic maps are therefore an indispensable asset in an NSDI. They link thematic information of any kind to a specific location. It is this location that is the linking pin to many other sources of information.

However, the reality of today is that many developing countries lack any up-to-date topographic maps. They have to rely on old maps, often produced more than 40 years ago; there is no money or, more importantly, no expertise available to update these maps. In other cases, they rely on online mapping sources like Google Maps, OpenStreetMap, etc. These are good, but consistency in quality is an issue.

Some countries already have topographic maps, but these date back from colonial times, and were not updated ever since. Others produce specific map series but are depending on the availability of reliable source material, like aerial photos and satellite imagery, purchased by the government. Or in some cases they have to organize partnerships with other national institutions to be able to purchase the necessary photo's or imagery. Regular maintenance of these maps is then often a real issue.

In general, every country has its own development stage, but when it comes to topographic mapping, it can be classified into 4 stages:

1. No topographic map available

2. Out of date analogue topographic map available

3. Digital, but out of date topographic map available

4. Digital and recent topographic map available

This paper describes these different stages of official map production that exist in countries around the world, each stage with its own characteristics, timeframe, roadmap and needs. It is not focusing on the technology but concentrates on the institutional aspects of topographic map production and what could be done to develop the production processes into sustainable work procedures. 